\title{
The Impact of Gonadal Hormones on the Expression of Human Neurological Disorders
}

\author{
Hyman M. Schipper \\ Lady Davis Institute, Jewish General Hospital, and Department of Neurology and Neurosurgery, McGill University, \\ Montreal, Que., Canada
}

\section{Key Words}

Alzheimer disease · Epilepsy · Estrogen · Menopause .

Menses · Movement disorder · Multiple sclerosis · Neoplasm · Oral contraceptive

\begin{abstract}
The effects of gonadal steroids on neurological well-being and disease constitute a rich and rapidly expanding area of basic and clinical neuroscience. Gonadal hormones exert potent effects on monoaminergic, cholinergic and peptidergic pathways as well as neurosteroidogenesis which, in turn, impact normal brain organization and function. A spectrum of human neurological conditions are influenced by hormonal fluctuations associated with the menstrual cycle, pregnancy, the menopause and use of oral contraceptives. An appreciation of these relationships may facilitate the development of specific hormonal and anti-hormonal therapies for neurological disorders as disparate as catamenial epilepsy and acute intermittent porphyria.

๑) 2015 S. Karger AG, Basel
\end{abstract}

\section{Preamble}

While engaged in a neuroendocrinology fellowship at Tufts University in Boston (1987-1988), the author's mentor, Seymour Reichlin (fig. 1), to whom this paper is dedicated, once remarked that 'neuroendocrinology is a discipline in search of a disease' [pers. commun.]. Although the clinical material encountered by a 'practicing' neuroendocrinologist may be construed as relatively limited in scope and volume, this situation changes dramatically, at least for the neurologist, when the purview of clinical neuroendocrinology is expanded to encompass the myriad influences of circulating gonadal hormones on the expression of neurological disease. In this article, we provide a general overview of fundamental sex steroid-neural interactions followed by a review of the broad spectrum of central and peripheral nervous system disorders impacted by fluctuations in the reproductive hormonal milieu. This review focuses largely on steroid-neural interactions in women, as the relatively nonfluctuating (tonic) profile of androgen secretion in men renders the impact of testicular hormones on the natural history of neurological diseases more difficult to discern.

\section{Sex Steroid-Neural Interactions}

Estrogens, progestins and androgens represent the three major classes of endogenous gonadal steroids in mammals of both sexes. The reproductive steroids are synthesized and secreted by the ovaries, testes and adrenal glands, and may also be derived from the enzymemediated metabolism of prohormones in extraglandular

\section{KARGER}

E-Mail karger@karger.com

www.karger.com/nen
(C) 2015 S. Karger AG, Basel

0028-3835/15/1035-0417\$39.50/0
Hyman M. Schipper

Lady Davis Institute for Medical Research

Jewish General Hospital

3755 Cote Sainte-Catherine Road, Montreal, QC H3T 1E2 (Canada)

E-Mail hyman.schipper@ mcgill.ca 


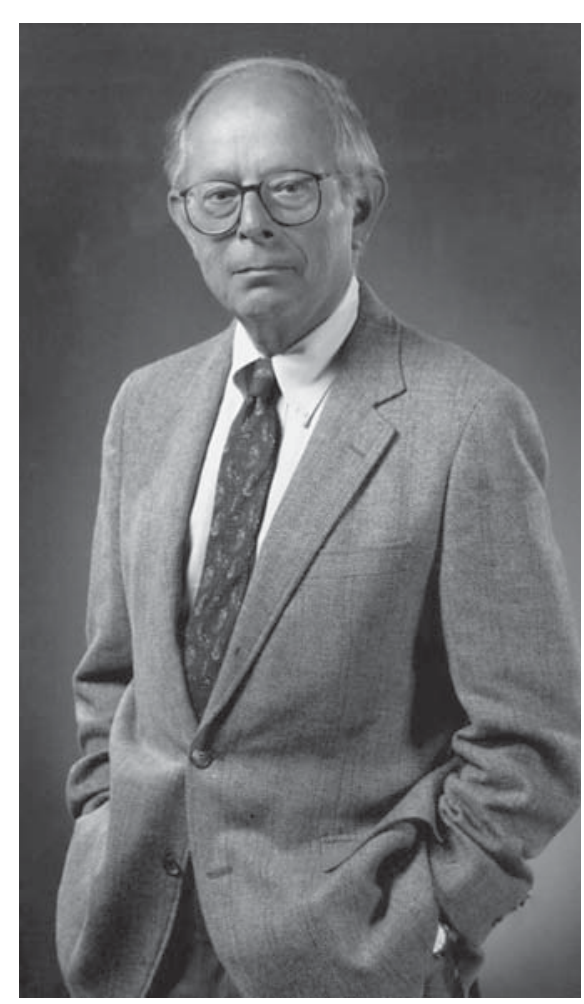

Fig. 1. Seymour Reichlin, MD, PhD, MACP. Courtesy of Dr. Ron Lechan.

tissues. Notable examples of the latter include the aromatization of the androgens, testosterone and $\delta_{4}$-androstenedione to $17 \beta$-estradiol and estrone, respectively, in brain and adipose tissue. Approximately $98 \%$ of the plasma gonadal hormone pool is protein bound and functionally inert. The remaining 'free' fraction is highly lipophilic and readily traverses the blood-brain barrier and neuronal cell membranes. Gonadal hormones form complexes with specific receptor proteins within the cytoplasm or nucleus of the target cells. The steroid-receptor complexes induce or suppress the transcription of various genes by interacting with steroid response elements within the genes' promoter regions. Sex steroids may also impact neural functions by epigenetic modulation of cellular DNA methylation status [1]. In neurons, gonadal steroids regulate the biosynthesis of enzymes and structural proteins concerned with energy metabolism, cell membrane function, neurotransmission and hormonal sensitivity [2].

In male and female mammals, estrogen-binding neurons are concentrated in the medial amygdala, preoptic area, medial basal hypothalamus and circumventricular organs. To a lesser extent, estrogen-binding neurons also occur in the hippocampus, basal forebrain, several thalamic nuclei, sensory regions of the brainstem and spinal cord, and the neonatal neocortex. The topographies of the estrogen, progestin and androgen target neurons exhibit considerable overlap within the mammalian neuraxis. In addition to neurons, some periventricular astrocytes also contain gonadal steroid receptors and undergo biochemical and morphological changes after hormonal exposure [2-4]. These latter observations are consistent with the fact that sex hormones may influence the growth and differentiation of certain human glial tumors (see the section Other Neoplasms).

In addition to their 'classic', receptor-mediated interactions with neural target tissues, gonadal hormones may directly or indirectly modulate neuronal discharges via rapid, nongenomic actions. An important pathway by which this occurs entails the central generation of neurosteroids from ovarian, testicular and adrenal hormone precursors. Neurosteroids can be categorized as (a) pregnane neurosteroids [e.g. allopregnanolone and allotetrahydrodeoxycorticosterone (THDOC), derived from progesterone and deoxycorticosterone, respectively], (b) androstane neurosteroids (e.g. androstanediol and etiocholanone, metabolites of testosterone) and (c) sulfated neurosteroids (e.g pregnanolone sulfate and dehydroepiandrosterone sulfate). Neuroglial cells (astrocytes, oligodendrocytes) and certain neuronal populations are enriched for key enzymes (5a-reductase, 3ahydroxysteroid oxidoreductase) which catalyze the interconversion of precursor hormones to neurosteroids [5-7]. Neurosteroids rapidly modulate neuronal firing by enhancing or attenuating inhibitory GABA-A receptor-mediated chloride (and other ion) conductance at the neuronal membrane. By acting as positive allosteric modulators of GABA-A receptors, allopregnanolone, THDOC and androstanediol augment GABAergic neurotransmission and thereby dampen neuronal excitability. Contrariwise, the sulfated neurosteroids may facilitate central excitation by curtailing GABAergic transmission and augmenting calcium flux through the NMDA (glutamate) receptor [5, 6]. By impacting GABAergic and glutamatergic pathways, allopregnanolone and THDOC elicit sedative-hypnotic, anticonvulsant and anxiolytic effects relevant to the pathophysiology of epilepsy (see the section Reproductive Hormones and Epilepsy) and various mood disorders. On the other hand, the net excitatory influences of pregnanolone sulfate and dehydroepiandrosterone sulfate may bolster memory functions compromised by Alzheimer disease 
and related dementias (section Reproductive Hormones and Alzheimer Disease) and exacerbate anxiety disorders $[5,6,8]$.

\section{Organizational Effects}

Gonadal steroids impart both organizational and activational influences within the nervous system. Organizational effects connote the irreversible differentiation of neural circuitry accruing from exposure to gonadal hormones during critical periods of brain development. A prime example of this are the roles estrogens and aromatizable androgens play in the sex-specific organization of the hypothalamic-pituitary-gonadal axis, processes which are better understood in rodents than in primates.

\section{Rodents}

In female rats and mice during the first week of life (neonatal 'critical period'), estradiol secreted by the ovaries is bound to circulating $\alpha$-fetoprotein which limits the hormone's ability to traverse the blood-brain barrier. The hypothalamic pathways responsible for pituitary gonadotropin regulation are intrinsically 'female' in organization and release gonadotropin-releasing hormone ( $\mathrm{GnRH})$ in a pulsatile (phasic) fashion. The latter is necessary for evoking the surge in luteinizing hormone required for ovulation. a-Fetoprotein levels decline postpartum, thereby allowing ovarian estrogen to modulate the brainpituitary axis after puberty. Testosterone administered to female rodents during the critical period does not bind to $\alpha$-fetoprotein and readily accesses the developing hypothalamus. Within the immature hypothalamus, testosterone is metabolized to estradiol by the enzyme aromatase. Ironically, this estradiol 'masculinizes' the gonadotropinregulating hypothalamic circuitry, resulting in permanent, nonpulsatile (tonic) release of GnRH and LH. In the absence of phasic LH secretion, at puberty the animal develops anovulatory sterility and multicystic ovaries. In neonatal male rodents, testosterone secreted by the testes during the critical period does not bind a-fetoprotein, aromatizes to estradiol within the hypothalamus and reorganizes the intrinsically 'female' circuitry to express 'male' (tonic) patterns of GnRH and LH secretion. The latter support normal levels of testicular androgen production at puberty. Genetic male rodents castrated at birth or treated with antiestrogens or aromatase inhibitors during the critical period will exhibit 'female' (pulsatile) patterns of GnRH-LH secretion at puberty [9]. In addition to the perinatal sensitization window, there appears to be additional, genetically and epigenetically mediated 'fine-tuning' of rodent brain masculinization/fem- inization resulting from surges in gonadal steroid production at puberty $[1,10]$. In adult rats and mice, estrogens may accelerate aging-related cytopathological changes in the mediobasal hypothalamus that may contribute to the onset of reproductive senescence $[4,11,12]$.

\section{Nonhuman Primates}

The organization of the brain-pituitary-gonadal axis in primates exhibits certain fundamental differences from that of rodents: In contradistinction to rats and mice, the structural and irreversible effects of gonadal hormones on the neuroendocrine hypothalamus and other sex steroid targets within the developing monkey brain occur exclusively during the prenatal period. Moreover, circulating androgens, rather than their estrogenic metabolites, mediate the sexual differentiation of the developing monkey brain. Brain aromatase activity appears to be relatively unimportant in prenatal primates as both testosterone (an aromatizable androgen) and 5a-dihydrotestosterone (a nonaromatizable androgen) are equipotent in organizing the developing neural circuitry [13, 14]. In rhesus monkeys, exposure to prenatal androgens can both masculinize and defeminize various reproductive and nonreproductive juvenile and adult behaviors [13]. Finally, unlike the situation in rodents, fetal androgen exposure does not abrogate the positive feedback effect of estradiol on hypothalamic release of $\mathrm{GnRH}$ in adult primates [15].

\section{Humans}

Sexually dimorphic areas have been delineated in the human brain, including the bed nucleus of the stria terminalis, the sexually dimorphic nucleus of the preoptic area, sub-regions of the hypothalamic suprachiasmatic nucleus and several white matter tracts [16]. In a recent study of human neonates using high-resolution brain MRI and surrogate markers of intrauterine androgen exposure, structural differences between the sexes were documented in dorsolateral prefrontal, medial temporal, motor and visual cortices [17]. The authors found that while androgen exposure exerted minor gender-related influences on cortical gray matter volumes, other factors were largely responsible for cortical sexual dimorphism at this age. They concluded that 'sexual dimorphism of the [human] brain reflects the dynamic interplay of multiple mechanisms both biological (e.g. prenatal hormone production, neonatal hormone production, pubertal hormone production, direct sex-chromosome effects) and experiential (e.g. interactive behavior, exposure to physical hazards, culturally influenced lifestyle differences (ibid.))'. Nonphysio- 
logical exposure to circulating gonadal hormones in utero (e.g. after maternal exposure to diethylstilbestrol) or during infancy (e.g. in children with congenital adrenal hyperplasia) may interfere with the normal development of one or more sexually dimorphic brain regions and alter the expression of gender-associated behaviors [16].

\section{Activational Effects}

'Activational effects' connote the largely reversible neurophysiological influences mediated by gonadal hormones within the mature nervous system. The latter are essential for the maintenance of normal patterns of sexual, aggressive, cognitive and autonomic behaviors and regulation of the brain-pituitary-gonadal axis. As in the case of other endocrine systems, it is often the rate of change in ambient sex hormone concentrations, rather than absolute levels per se, which determines the valence and robustness of attendant biological responses. In women of reproductive age, circulating estradiol concentrations increase during the late follicular phase of the cycle and peak just prior to ovulation. A smaller but more sustained rise in plasma $17 \beta$-estradiol occurs during the luteal phase. Progesterone levels are negligible during the follicular phase and increase considerably during the luteal phase in synchrony with the second $17 \beta$-estradiol surge. In the late luteal phase, a decline in sex hormone levels triggers the menstrual flow. In adult men, testosterone secretion by testicular Leydig cells, circulating levels of the androgen and the latter's influences on androgen target tissues are mainly 'tonic' in nature.

Germane to the central theme of this paper, hormonal changes linked to specific phases of the menstrual cycle, pregnancy, the menopause and exposure to exogenous sex hormones may impact the release and metabolism of neurotransmitters and neuromodulators and thereby give rise to, or modify, a host of neurological and neuropsychiatric conditions. All major categories of neurological affliction (vascular, metabolic, inflammatory, degenerative, etc.) are considered in this review, with emphasis on their expression in women. The article begins with disorders of the central nervous system (CNS) and progresses to those affecting peripheral nerve and muscle. In each section, common conditions encountered in clinical practice are reviewed before, and in greater detail than, the rarer entities. Nervous system disorders documented to benefit from specific hormonal and anti-hormonal therapies are discussed where appropriate. The roles of gonadal hormones in human psychiatric conditions (e.g. depression, psychosis, the premenstrual syndrome) were considered elsewhere [2].

\section{Sex Hormones and Migraine}

\section{Epidemiology}

Migraine is about three times as common in adult women as in men. Perimenstrual worsening of headaches (catamenial migraine) occurs in approximately $60 \%$ of female migraineurs. The severity or frequency of migraine attacks often diminishes with pregnancy, particularly in individuals whose headaches are associated with the menstrual cycle. Many women whose migraine condition is attenuated by gestation have relapses at the time of parturition. Breastfeeding may protect against migraine recurrence in some women. Migraine may occasionally arise or worsen during gestation or the perimenopausal period $[18,19]$. Menstruation, pregnancy and the menopause may also influence cluster headache, other autonomic cephalalgias and hemicrania continua [20].

\section{Pathophysiology}

The decline in plasma estradiol (but not progesterone) in the late luteal phase plays an important role in the expression of catamenial migraine. In pregnancy, the absence of rhythmic estrogen 'withdrawal' may be responsible for the reduction in migraine activity. Estrogens may influence migraine by acting directly on vascular smooth muscle or by modulating the activity of vasoactive substances at the neurovascular junction. By altering central serotonin, prolactin, prostaglandin or opioid metabolism, perimenstrual fluctuations in circulating estrogens may also stimulate vasoregulatory elements in the hypothalamus or brainstem resulting in symptomatic alterations in cerebrovascular tone [20].

\section{Clinical Manifestations}

The clinical manifestations of hormonally associated migraine are similar to those of migraine in the general population. Women taking oral contraceptives may experience new-onset or exacerbation of migraine. Attacks tend to occur during the first few cycles (particularly on placebo days when estrogen levels are declining) and usually resolve on discontinuation of the contraceptive. Migraineurs who develop focal auras while taking oral contraceptives may be at elevated risk of infarction in the affected brain regions [20].

\section{Treatment}

Perimenstrual migraine can usually be managed with standard dietary, psychological and pharmacological modalities employed in the general migraine population. Serotonin 5-HT1D (presynaptic autoinhibitory) receptor 
agonists show similar efficacy in noncatamenial and menstrual migraine [21]. Late luteal phase therapy with prostaglandin inhibitors (nonsteroidal anti-inflammatory agents) and mild diuretics may be helpful in refractory cases of severe catamenial migraine. Oral contraceptives may worsen migraine and probably should not be used in the treatment of this disorder; estrogen implants and the anti-estrogen tamoxifen have yielded contradictory results. There are reports of significant symptom alleviation in women with menstrual migraine following treatment with the testosterone derivative, danazol or the dopamine agonist bromocriptine [20,22]. To avoid risks of teratogenicity, nonpharmacological approaches to initial management of gestational migraine (e.g. relaxation training, biofeedback) should be considered. Acetaminophen with codeine or nonsteroidal anti-inflammatory agents can be used for more severe attacks. Meperidine, morphine, chlorpromazine or prednisone may need to be administered for protracted, refractory migraine (status migrainosus) in pregnancy [23]. Hormone replacement therapy (HRT) may be effective in perimenopausal migraine, but this must be weighed against the risk of developing breast cancer. In women with perimenopausal migraine and hot flashes, venlafaxine or fluoxetine may be of benefit [24].

\section{Gonadal Hormones and Stroke}

\section{Epidemiology}

Until age 85 years, men are at higher risk for atherosclerosis and ischemic stroke than women. Women exhibit 'spikes' in stroke risk in the peurperium and perimenopausally [25]. Exposure to oral contraceptives has been implicated as an important risk factor in thromboembolic cerebral infarction, cerebral venous thrombosis and subarachnoid hemorrhage. Age older than 35 years, hypertension, cigarette smoking and migraine may further increase the risk of stroke in patients on 'the Pill' [2, 26]. A recent decline in rates of thromboembolic disease among oral contraceptive users has been attributed to the lower doses of estrogen in contemporary preparations (e.g. 25-35 $\mu \mathrm{g}$ as opposed to 50-75 $\mu \mathrm{g}$ ). Indeed, use of ultra-low-dose oral contraceptives $(<25 \mu \mathrm{g}$ ethinyl estradiol) may not augment stroke risk in normotensive nonsmokers [27]. There are conflicting data concerning the impact of HRT on stroke incidence and severity, with reports of neutral, increased and decreased stroke risk accruing from this intervention. Importantly, several large randomized controlled studies indicated that HRT with $17 \beta$-estradiol or conjugated equine estrogen, with or without medroxyprogesterone acetate, may worsen outcomes in women at high risk for stroke or coronary artery disease $[28,29]$. Of note, men with the common ESR1 c.454-397CC variant of the estrogen receptor- $\alpha$ (ESRa) gene may be more susceptible to ischemic stroke than men with other ESRa genotypes after adjusting for age, smoking, diabetes, hypertension and blood lipids [30].

\section{Pathophysiology}

Sex steroids may impact atherosclerosis and attendant ischemic stroke by influencing blood coagulation cascades, platelet function, lipid profiles, inflammatory processes within the atheroma and vascular reactivity [25, 31]. Estrogen induces hypercoagulability by increasing plasma levels of fibrinogen and clotting factors VII, VIII, IX, X and XII; enhancement of platelet aggregation, and suppression of antithrombin III activity, plasminogen activating inhibitor- 1 levels and fibrinolysis. Data concerning the effects of estrogens on platelet responses are conflicting. Although the platelets of women exhibit greater reactivity than those of men, hypoestrogenemia may further augment platelet responsiveness and predispose postmenopausal women to ischemic stroke [25]. Estrogen-related hypercoagulability complicating pregnancy, the puerperium and use of hormonal contraceptives may predispose to thromboembolic stroke and cerebral venous infarction. Certain inheritable prothrombotic conditions (e.g. factor V Leiden, G20210A prothrombin or methylenetetrahydrofolate reductase C677T polymorphism) further augment the risk of ischemic stroke in oral contraceptive users [32]. Sex hormones may also influence athero-occlusive vascular disease by modulating inflammatory components of the plaque. Various immune cells within or surrounding the atheroma, including B cells, $T$ cells, dendritic cells and macrophages, express $\mathrm{ER} \alpha, \mathrm{ER} \beta$ and the androgen receptor. Estrogens may protect against atherosclerosis by inhibiting stressor-induced NFKB signaling in macrophages and the synthesis of its downstream proinflammatory products IL- $1 \beta$, IL- 6 and TNFa [31]. Estrogens also increase dendritic cell differentiation and production of the anti-inflammatory molecules, Treg, IL-4, IL-10 and TGF $\beta$ by M 2 macrophages, and decrease deposition of atherogenic oxidized lowdensity lipoprotein within the vascular wall. Androgens, on the other hand, may accelerate atherosclerosis by facilitating innate immune cell activation and the elaboration of proinflammatory cytokines $[31,33]$. Progestins may contribute to the danger of cerebral infarction by promoting dyslipidemia, hypercoagulability and hypertension $[34,35]$. The mechanisms by which female go- 
nadal steroids predispose to bleeding from aneurysms and arteriovenous malformations remain controversial. Fluctuating ovarian hormone levels may compromise the integrity of cerebral arterial walls akin to their effects on endometrial spiral arteries. Gonadal hormones may also exert direct trophic influences on arteriovenous malformations analogous to their effects on other highly vascularized lesions such as gingival epulis, spider angiomas and meningiomas [20].

\section{Clinical Manifestations}

Clinically, ischemic strokes attributed to oral contraceptive use have been localized to the carotid (usually the middle cerebral artery) and vertebrobasilar systems. Neuroimaging or pathological evidence of disseminated vascular disease is usually absent in young women with oral contraceptive-related stroke. Rarely, subarachnoid hemorrhage may be cyclic in women with hormone-sensitive ectopic endometriomas of the spinal canal [20].

\section{Treatment}

Exogenous gonadal hormones should be immediately discontinued and may be prohibitive for future use in young women presenting with a stroke syndrome. The management of ischemic stroke related to gonadal hormone exposure should otherwise adhere to general guidelines and may invoke standard pharmacotherapy (antiplatelet agents, anticoagulants, fibrinolytics), interventional neuroradiology (stents) and rehabilitation. Both men and women presenting early with acute ischemic stroke may benefit from tissue plasminogen activator (tPA). However, re-canalization responses (reperfusion) following both intravenous and intra-arterial tPA administration tend to be more robust in women [36]. Although rarely encountered, periodic subarachnoid hemorrhage due to spinal canal endometriosis may respond to progestins, danazol, GnRH agonist or oophorectomy [20].

\section{Gonadal Hormones and Movement Disorders}

\section{Chorea}

Epidemiology

Pregnancy and oral contraceptive use may be complicated by the appearance of choreiform (jerky, nonrhythmic) movements involving the face and extremities. Gestational and oral contraceptive-related choreas are more prevalent in individuals with prior rheumatic fever and Sydenham's chorea [37]. Oral contraceptives may engender chorea in women with a history of congenital cya- notic heart disease and Henoch-Schönlein purpura and amplify dyskinesias in chorea-acanthocytosis [20, 38]. Twenty percent of women may experience relapses with subsequent pregnancies. Women with oral contraceptive-related dyskinesias are more prone to develop chorea gravidarum and vice versa [20].

\section{Pathophysiology}

Altered hormonal patterns characteristic of pregnancy and ingestion of steroid contraceptives may unmask latent chorea by facilitating dopaminergic neurotransmission in basal ganglia previously injured by hypoxic or rheumatic encephalopathy [20].

\section{Clinical Features, Diagnosis and Treatment}

Women with gestational and contraceptive-related chorea may additionally exhibit fever, neuropsychiatric symptoms, dysarthria (slurred speech), pendular reflexes or limb hypotonia. Chorea gravidarum and contraceptive-related dyskinesias usually resolve by parturition or after discontinuation of the medication, respectively. In patients with suspected chorea gravidarum, appropriate clinical and laboratory investigations may be indicated to exclude other etiologies, such as hyperthyroidism, rheumatic fever, Wilson disease or systemic lupus erythematosus. As chorea gravidarum is usually self-limited, abortion or premature delivery is rarely required. In severe cases, neuroleptics (dopamine antagonists) may afford symptomatic relief. Individuals with a history of chorea gravidarum or contraceptive-induced dyskinesias should probably avoid further exposure to estrogen-containing medications [20].

\section{Parkinsonism}

Epidemiology

Idiopathic Parkinson disease is an aging-related neurodegenerative disorder that is more common in men than women with an incidence ratio of approximately 1.5:1 [39]. A large, recent study comparing drug-naïve men and women with early Parkinson disease matched for the degree of motor impairment revealed significant gender disparities in the prevalence of nonmotor symptoms: deficits in olfaction and in certain cognitive domains (global, memory, visuospatial) were more severe in men, whereas trait anxiety was greater in women [40]. Data concerning the impact of reproductive hormones on parkinsonism are conflicted. Early anecdotal reports suggested that exposure to exogenous estrogen may exacerbate idiopathic and neuroleptic-induced parkinsonism. However, more recent studies of premenopausal women 
with idiopathic Parkinson disease documented perimenstrual worsening of motor symptoms when estrogen titers were falling $[20,41]$. Postmenopausal HRT is variably reported as beneficial $[42,43]$, detrimental [44] or inconsequential [45] in women with Parkinson disease. Early menopause (natural or surgical) has been touted as a risk factor for the development of Parkinson disease [46, 47] which may be mitigated by postmenopausal estrogen replacement [47]. Conversely, no evidence of a salutary effect of estrogen on the risk of developing Parkinson disease could be adduced in a large prospective study [48]. In one case-control study, steroid contraception emerged as a susceptibility factor for the disease with an adjusted odds ratio of 3.27 (95\% CI: 1.24-8.59; $\mathrm{p}=0.01$ ) [49].

Pathophysiology

Clinical and experimental data indicate that estrogens may influence motor manifestations of parkinsonism by modulating dopaminergic tone within the nigrostriatum. But whether the estrogenic influences on dopaminergic neurotransmission in this disease are predominantly stimulatory or inhibitory remains uncertain [2]. In animal models of Parkinson disease, the neurosteroid allopregnanolone enhances neurogenesis in the substantia nigra, modulates dopamine release and improves motor control [8]. The latter findings may have clinical significance given that allopregnanolone concentrations are reportedly low in the plasma and cerebrospinal fluid of patients with idiopathic Parkinson disease [50, 51].

\section{Treatment}

Hormonal interventions are rarely indicated in the management of parkinsonism impacted by gonadal steroid fluctuations. In light of the data reviewed in the preceding section, Irwin et al. [8] have advocated clinical trials to investigate the potential neuroprotective and therapeutic benefits of allopregnanolone in subjects with Parkinson disease.

\section{Wilson Disease}

Epidemiology

Wilson disease is a rare inborn error of copper metabolism that is characterized by decreased blood ceruloplasmin levels, hepatic cirrhosis, corneal copper deposition (Kayser-Fleischer rings) and degenerative changes in the basal ganglia [20].

\section{Pathophysiology}

Movement disorders, seizures and psychosis result from the toxic effects of excessive copper deposition in neural tissues. Serum ceruloplasmin and copper levels may increase during pregnancy and after administration of steroid contraceptives in normal individuals and in patients with Wilson disease [20].

\section{Diagnosis and Treatment}

In women with Wilson disease, diagnosis may be delayed by 'normalization' of ceruloplasmin levels resulting from exposure to steroid contraceptives. This false normalization of blood ceruloplasmin concentrations confers no therapeutic advantage, and may in fact be associated with neurological deterioration (abnormal movements, seizures, psychosis) in some individuals [20]. It remains unknown whether gonadal hormones similarly raise blood ceruloplasmin titers in other conditions featuring low levels of the protein, such as acquired copper deficiency or hereditary hypoceruloplasminemia [52].

\section{Other Movement Disorders}

Fluctuating gonadal hormone levels have also been reported to influence symptoms in patients suffering from Tourette syndrome, tardive dyskinesia, familial episodic ataxia, hereditary and posthypoxic myoclonus, dominantly inherited myoclonic dystonia, hemiballismus, drop attacks and the neuroleptic malignant syndrome $[20,53,54]$.

\section{Reproductive Hormones and Epilepsy}

\section{Epidemiology}

Seizure disorders and their treatments may disrupt normal reproductive processes. Hypogonadotropic hypogonadism, the polycystic ovary syndrome and hyposexuality may be due to aberrant limbic discharges in patients with temporal lobe epilepsy [20]. Oral contraceptive failure occurs with increased frequency in epileptic women exposed to phenobarbital, primidone, phenytoin, carbamazepine and ethosuximide [55]. Topiramate and felbamate may influence gonadal hormone pharmacokinetics and thereby compromise contraceptive efficacy [56]. Valproic acid does not interfere with the Pill's efficacy but may cause hyperandrogenism and polycystic ovaries [57]. Failure of oral contraception does not appear to be a concern in women taking vigabatrin, gabapentin, levetiracetam, clobazam, zonisamide or lamotrigine $[55,58,59]$. Tiagabine may elicit breakthrough bleeding, but the overall impact of this drug on gonadal steroid metabolism is thought to be minimal [60]. 
The natural history of epilepsy and its management may be greatly influenced by specific phases of the reproductive cycle and exposure to hormonal contraceptives. Various seizure disorders may worsen premenstrually (catamenial epilepsy), at ovulation or during pregnancy. Menstrual irregularity at ages 18-22 years was associated with an increased risk of epilepsy (RR 1.67, 95\% CI 1.122.51) in a large study [61]. The influences of the menstrual cycle and of oral contraceptive preparations on anticonvulsant disposition appear to be of minor clinical significance. On the other hand, gestational plasma concentrations of phenobarbital, phenytoin and valproic acid may decrease by $30-40 \%$ percent of prepregnancy levels, with a lesser decline in carbamazepine. Primidone concentrations remain fairly stable during pregnancy, but the level of primidone-derived phenobarbital may be diminished [20].

\section{Pathophysiology}

Most anticonvulsants implicated in oral contraceptive failure induce the hepatic cytochrome P450 microsomal enzyme system, which, in turn, accelerates catabolism of reproductive steroids. Anticonvulsants may also (a) stimulate the production of sex hormone-binding globulins, resulting in diminished concentrations of circulating free (active) hormone and (b) facilitate the clearance of gonadal hormones by influencing their sulfate conjugation and glucuronidation in the liver and gut [20].

Estrogens and progestins have epileptogenic and anticonvulsant properties, respectively. Estrogens and the sulfated neurosteroids (see the section Sex Steroid-Neural Interactions) enhance glutamatergic and attenuate GABAergic neurotransmission, favoring epileptogenesis; progesterone and certain pregnane and androstane neurosteroids have the opposite effects $[6,62]$. Perimenstrual seizure activity may be precipitated by rising estrogen:progesterone ratios during the late luteal phase. Conceivably, elevated estrogen:progesterone ratios characteristic of the polycystic ovary syndrome may explain the relatively frequent association of this infertility condition with temporal lobe epilepsy. Estrogen-progestin contraceptives do not significantly worsen seizure control in women with epilepsy [55]. Regarding gestational epilepsy, inadequate anticonvulsant levels, sleep deprivation and stress may be more salient than direct hormonal epileptogenesis. Decreased drug compliance, bioavailability, an increased volume of distribution and enhanced metabolic clearance contribute to the fall in anticonvulsant levels during pregnancy [63].

\section{Treatment}

Approaches to the management of catamenial epilepsy include (1) premenstrual or periovulatory supplementation of anticonvulsant doses or addition of an adjunctive anti-epileptic drug (e.g. clobazam); (2) cyclic administration of a mild diuretic such as acetazolamide (which has weak anticonvulsant activity) and (3) progesterone supplementation by mouth or suppository $[64,65]$. More frequent monitoring of anti-epileptic drug levels during pregnancy is prudent, with dosage adjustments (usually increments) implemented as necessary. Early-phase human clinical trials have been conducted assessing the anticonvulsant effects of the allopregnanolone analog ganaxolone (3a-hydroxy-3 $\beta$-methyl-5 $\alpha$-pregnane-20-one). Ganaxolone is a positive allosteric modulator of GABA-A receptors (see the section Sex Steroid-Neural Interactions) which has shown promise in animal models of epilepsy. In randomized, placebo-controlled trials, the synthetic neurosteroid diminished seizure activity in adults with drug-resistant partial-onset seizures and children with refractory infantile spasms. Ganaxalone was safe and well-tolerated, with dizziness and fatigue being the most frequently reported adverse effects [66-68]. Importantly, ganaxalone lacks hormonal activity and therefore does not expose patients to the potential risks of progestin therapy [69].

\section{Gonadal Hormones and Multiple Sclerosis}

\section{Epidemiology}

Multiple sclerosis (MS) is an immune-mediated demyelinating disorder of the CNS that is most often diagnosed in men and women during their reproductive years. An association between MS and certain ESR1 gene polymorphisms has been documented in some studies $[70,71]$, but not others [72]. Contrary to earlier medical dogma, the overall impact of one or more pregnancies on MS-related morbidity is minimal [73]. There is a tendency for MS to worsen during the first 3 postpartum months that is counterbalanced by amelioration of disease activity in the third trimester [74]. Oral contraceptive exposure may delay the onset of MS but does not appear to influence the risk of developing the disease [75].

\section{Pathophysiology}

Attenuation of third-trimester disease activity in MS (and other immune-mediated conditions) is likely due to relative maternal immunosuppression that serves to obviate rejection of the semi-allogenic fetus. Circulating fac- 
tors that may mediate gestational immunosuppression include estradiol, progesterone, $\alpha$-fetoprotein, pregnancy-associated glycoprotein, human chorionic gonadotropin, human placental lactogen, 1,25-dihydroxyvitamin $\mathrm{D}_{3}$, cortisol and interleukin-10 $[20,26]$. Neurosteroids have been implicated in the pathogenesis of MS inasmuch as (a) allopregnanolone may be deficient in the white matter of MS patients and (b) allopregnanolone stimulates neuronogenesis, oligodendrogliogenesis and myelin formation, suppresses neuroinflammation and modulates the innate immune response $[8,76]$.

\section{Treatment}

MS attacks in pregnancy can be treated with intravenous steroids. Interferons should be discontinued at least 3 months before planned conception and should not be administered during pregnancy or while breastfeeding [20]. In an Israeli study, none of 14 pregnant women with relapsing-remitting MS who were treated with prophylactic intravenous immunoglobulins immediately after delivery exhibited disease relapse within the subsequent 6 months [77]. Preliminary reports of potentially beneficial effects of oral estriol in women with MS and transdermal testosterone in men with the disease [78] require confirmation.

\section{Reproductive Hormones and Alzheimer Disease}

\section{Epidemiology}

Alzheimer disease is a common dementing illness characterized by progressive neuronal degeneration, gliosis, marked depletion of acetylcholine and other neurotransmitter disturbances and the accumulation of senile (amyloid) plaques and neurofibrillary tangles in discrete regions of the basal forebrain, hippocampus and association cortex [79]. Early clinical investigations suggested that estrogen replacement therapy may enhance cognitive performance (especially attention, verbal memory and language function) and increase responsiveness to acetylcholinesterase inhibitors in menopausal women with Alzheimer disease [80-84]. Furthermore, postmenopausal HRT was associated with a significantly reduced risk of developing Alzheimer disease in several case-controlled studies [85-87], in a meta-analysis of 12 observational studies [88] and in initial prospective studies $[89,90]$. There was also some indication of enhanced cognition in elderly men with Alzheimer disease or mild cognitive impairment treated with estrogen [91] or testosterone $[92,93]$. Despite this initial optimism, cognitive function scores were no different in women with coronary artery disease who received estrogen and progestin than in placebo-treated controls in the randomized Heart and Estrogen/Progestin Replacement Study (HERS) [94]. Moreover, in the large Women's Health Initiative Memory Study (WHIMS), the hazard ratios for development of dementia were 1.49 for women randomized to receive $0.625 \mathrm{mg}$ conjugated equine estrogen and 2.05 for those receiving $0.625 \mathrm{mg}$ estrogen plus $2.5 \mathrm{mg}$ medroxyprogesterone acetate relative to placebo-treated controls [95]!

\section{Pathophysiology}

Data amassed from fundamental studies suggest that estrogens could theoretically improve cognition in Alzheimer disease by (a) promoting neuritic arborization and dendritic spine formation, (b) providing trophic support for cholinergic neurons and $\mathrm{N}$-methyl-D-aspartate receptors, (c) attenuating $\beta$-amyloid deposition, neuroinflammatory responses and oxidative neural damage and (d) improving cerebral blood flow and glucose utilization [20]. Downmodulation of brain $\beta$-amyloid deposition by androgen exposure has also been reported [96]. Neurosteroids may also contribute to cognitive health insofar as allopregnanolone increases hippocampal neurogenesis, dampens microglial activation (neuroinflammation), decreases $\beta$-amyloid pathology and reverses learning and memory deficits in animal models of Alzheimer disease [8]. Moreover, there are reports of reduced levels of allopregnanolone in the prefrontal cortex and subnormal concentrations of DHEA-S in the plasma and cerebrospinal fluid of Alzheimer subjects [6].

\section{Treatment}

On the basis of the disappointing data derived from large, randomized, placebo-controlled trials (see above), the third Canadian Consensus Conference for the Diagnosis and Treatment of Dementia (2006) recommended against the use of estrogen/progestin replacement therapy for reducing the risk of dementia in postmenopausal women. However, some have recently argued that the large therapeutic trials may have missed a critical perimenopausal 'window' during which HRT may protect against the development of Alzheimer disease [97, 98]. Of note, administration of pregnanolone ameliorated cognitive deficits in individuals with schizophrenia [99]. This observation, in conjunction with the preclinical and human biochemical data summarized in the preceding section, raises the possibility that exogenous neurosteroids may preserve or enhance cognition in patients with Alzheimer disease and other neurodegenerative de- 
mentias [8]. In one small, placebo-controlled study, 6 months of treatment with DHEA failed to confer significant cognitive benefits in patients with Alzheimer disease [100].

\section{Gonadal Hormones and Sleep Disorders}

\section{Epidemiology}

In women, sleep architecture is impacted by puberty, menstruation, pregnancy and the menopause. Overall, sleep-associated complaints are more prevalent in women than men. Gender differences in sleep patterns become apparent after puberty and may contribute to the risk of developing sleep disorders [101]. For example, insomnia is more common in women than men, with the prevalence between the sexes diverging with advancing age. Restless legs syndrome slightly favors women, whereas obstructive sleep apnea and rapid eye movement sleep behavior disorder occur more frequently in men [101, 102].

\section{Pathophysiology}

The mechanisms by which altered gonadal hormone concentrations and their influences on neural targets within the diencephalon and brain stem impact human sleep physiology remain poorly understood. Hypogonadism in women may disrupt normal sleep architecture by increasing mean sleep latencies, curtailing epochs of rapid-eye-movement sleep and facilitating nocturnal movement arousals [103]. The preponderance of obstructive sleep apnea in men may be dependent not only on disparities in the gonadal steroid milieu but also on sex differences in local neuromuscular reflexes and central ventilatory control [101].

\section{Treatment}

Combined estrogen-progesterone therapy attenuated breathing irregularities, periodic limb movements, nocturnal arousals, hot flashes and bruxism (teeth grinding) in a study involving 33 postmenopausal women [104]. In patients with central sleep apnea, progestins may alleviate hypoventilation by providing stimulatory drive to brainstem respiratory centers. The administration of progesterone to healthy men decreases vigilance during wakefulness, an effect possibly mediated by the GABAergic agonists, pregnanolone and allopregnanolone [105]. In one report, obstructive sleep apnea resolved in a nonobese woman following excision of a benign, testosterone-producing ovarian tumor [106].

\section{Gonadal Hormones and Nervous System Neoplasms}

\section{Meningiomas}

Epidemiology

Meningeal tumors are more prevalent in women than men of reproductive age. Meningiomas may occur more commonly in women who are obese or have hormonedependent breast carcinoma [20]. An increase in the incidence of meningioma in women receiving HRT was reported in a large Finnish study [107].

\section{Pathophysiology}

A significant proportion of human meningioma specimens express progestin- and, to a lesser extent, estrogenand androgen-binding proteins. These steroid-binding proteins likely mediate the effects of gonadal hormones on meningioma growth and differentiation. Higher circulating estrogen levels derived from the aromatization of androstenedione to estrone in adipocytes may explain the higher prevalence of meningiomas in obese individuals [20]. Perimenstrual and gestational changes in tumor size may be due to direct trophic effects of gonadal hormones on meningioma cells, steroid-induced fluid retention by the tumor or increased vascular engorgement of the lesion [108].

\section{Clinical Manifestations and Treatment}

Women may experience exacerbations of symptoms related to meningiomas in the luteal phase of the menstrual cycle. There is also clinical and radiological evidence for the rapid growth of meningiomas during pregnancy, followed by their spontaneous regression postpartum [109]. Progesterone receptor-negative meningiomas tend to display greater mitotic indices and necrosis [110], a higher propensity for brain invasiveness and shorter disease-free intervals [111]. The antiprogestin agent RU486 has been reported to stabilize growth or induce regression of meningiomas. However, patients on longterm RU486 therapy may require glucocorticoid replacement to offset the drug's anti-glucocorticoid effects [112]. Although meningiomas may be encountered more frequently in women receiving HRT [107], this observation should not influence the practice of HRT as the overall prevalence of these tumors remains very low in this population [113].

\section{Other Neoplasms}

Astrocytomas may selectively bind estrogens, progestins or androgens. In astroglial neoplasms, expression levels of estrogen receptor- $\beta$ may vary inversely with the 
degree of histopathological dedifferentiation and malignant behavior [114]. Astrocytomas have been reported to expand during pregnancy and regress in the puerperium. Clinical and radiological stabilization of astrocytomas and glioblastoma multiforme has been reported in some patients following treatment with the anti-estrogen tamoxifen [115-117]. In this regard, the radiosensitizing effects of tamoxifen or its inhibitory effects on protein kinase $c$ activity may be more important than its antiestrogenic properties [20]. The presence of gonadal steroid receptors or biological responsiveness to reproductive hormones has also been described in cases of pituitary adenomas, acoustic neuromas, oligodendrogliomas, anaplastic ependymomas, lymphomas, hemangioblastomas, primitive neuroectodermal tumors and breast cancer metastases to the neuraxis [20,118-120].

\section{Gonadal Hormones and Neuromuscular Disorders}

\section{The Porphyrias}

Pathophysiology, Clinical Manifestations and

Diagnosis

The porphyrias feature enhanced production of porphyrin precursors and porphyrins accruing from enzymatic defects in heme biosynthesis. Sensorimotor and autonomic neuropathies, neuropsychiatric symptoms and seizures are frequent neurological manifestations of certain porphyrias. Estradiol and other steroid hormones may trigger porphyric crises by inducing the heme biosynthetic enzyme $\delta$-aminolevulinic acid synthase. In women with acute intermittent porphyria, cyclical attacks of neuropathy and other neurological symptoms may occur during the late luteal phase or at ovulation. Diagnosis is aided by measurement of blood or urinary porphyrins and confirmed by genetic testing $[20,26]$.

\section{Treatment}

Chronic administration of GnRH agonists, such as leuprolide or D-His, downregulates gonadotrope $\mathrm{GnRH}$ receptors, resulting in long-term suppression of the pituitary-ovarian axis. In an early report [121], complete remission of catamenial acute intermittent porphyria was observed during 8 months of D-His treatment. Subsequent cases of perimenstrual acute intermittent porphyria and hereditary coproporphyria also exhibited beneficial responses to GnRH agonist therapy. Breast tissue atrophy, hot flashes and bone demineralization may complicate prolonged treatment with $\mathrm{GnRH}$ analogs [20, 122]. It may be prudent for asymptomatic relatives of pa- tients with genetic porphyrias to avoid exposure to oral contraceptives.

\section{Catamenial Sciatica}

Pathophysiology, Clinical Manifestations and

Diagnosis

Ectopic endometrial tissue (endometriosis) is sensitive to steroid hormones and exhibits sloughing and hemorrhaging during menses. Endometriosis may cause back or pelvic pain by invading lumbar vertebrae, the lumbosacral plexus or the sciatic nerve sheath. The latter elicits radicular pain that usually begins several days before the onset of menses and may continue until cessation of flow (catamenial sciatica). Leg weakness, numbness and loss of ankle reflexes may accompany the pain. Unlike discogenic radiculopathy, neuroimaging in endometriotic sciatica is generally unremarkable. Evidence of endometriosis elsewhere may or may not be apparent. Surgical exploration of the sciatic nerve may be required for diagnosis. The nerve appears blue in positive cases and incision of the sheath reveals a dark, hemorrhagic fluid. Characteristic glandular elements are observed at histopathology [26, 123].

\section{Treatment}

Symptoms of endometriotic sciatica are less likely to remit with bed rest than those of discogenic radiculopathy. The former may improve dramatically with standard therapy for endometriosis, including progestins, danazol, GnRH agonist or (in refractory cases) oophorectomy [20, 124].

\section{Other Neuromuscular Conditions}

Endogenous and administered gonadal steroids (mainly estrogens) may impact the natural history of the carpal tunnel syndrome, Bell's palsy and recurrent brachial plexopathy. The mechanism(s) underlying these effects may involve hormone-related soft tissue swelling and attendant nerve compression. Dysfunction of testicular peritubular myoid cells may contribute to the hypergonadotropic hypogonadism and impotence in men with myotonic dystrophy [125]. Hyperestrogenemia may occur in male patients with amyotrophic lateral sclerosis, bulbospinal muscular atrophy (Kennedy's syndrome), Kugelberg-Welander disease, Duchenne muscular dystrophy and POEMS (polyneuropathy, organomegaly, endocrinopathy, M-protein and skin changes associated with plasma cell dyscrasias). Whether the hyperestrogenemia plays any significant role in the pathogenesis of these neuromuscular disorders remains unclear [2]. 
High-dose testosterone was reported to ameliorate symptoms in a patient with bulbospinal muscular atrophy. Attenuation of the toxic gain of function ascribed to the mutated androgen receptor in this condition was invoked as a putative mechanism [126].

\section{Conclusions}

Gonadal hormones exert potent organizational and activational effects within the mammalian neuraxis and influence a wide spectrum of normal and abnormal neurological functions. The former may act directly on salient neural pathways or serve as precursors of bioactive neurosteroids. Relationships between endogenous and exogenous sex hormones and many neurological disorders, such as stroke, chorea, porphyria, epilepsy and migraine, are well established. In other conditions, including various movement disorders, CNS tumors, sleep apnea and MS, this relationship has not been confirmed but appears likely in the light of rapidly accumulating epidemiological, clinical and neuroimaging data. Changes in plasma reproductive hormone concentrations may also modulate the expression of diverse psychiatric states, including depression, psychosis, the premenstrual syndrome and anorexia nervosa [2]. Given the robust and fairly ubiquitous nature of steroid-neural interactions in humans, clinical inquiry into potential symptom fluctuations associated with the menstrual cycle, pregnancy, menopause and hormonal contraceptive exposure in women with neurological and psychiatric illness should become a matter of routine. Further delineation of the molecular mechanisms mediating the trophic and adverse effects of sex steroids on neurological well-being should inform future development of novel hormonal and anti-hormonal therapeutics for managing many of the afflictions discussed in this review.

\section{Acknowledgments}

This article is dedicated to Dr. Seymour Reichlin, a father of basic and clinical neuroendocrinology in America, on the occasion of his 90th birthday. The author is supported by the Canadian Institutes of Health Research, the Mary Katz Claman Foundation and the Oberfeld Family Research Fund.

\section{References}

1 Bale TL: Epigenetic and transgenerational reprogramming of brain development. Nat Rev Neurosci 2015;16:332-344.

2 Schipper HM: Sex hormones and the nervous system; in Aminoff MJ (ed): Neurology and General Medicine. Amsterdam, Elsevier, 2008, pp 409-426.

-3 Donahue JE, Stopa EG, Chorsky RL, King JC, Schipper HM, Tobet SA, Blaustein JD, Reichlin S: Cells containing immunoreactive estrogen receptor-alpha in the human basal forebrain. Brain Res 2000;856:142-151.

4 Schipper H: Role of peroxidase-positive astrocytes in estradiol-related hypothalamic damage; in Fedoroff S, Bernhard H, Juurlink J, Doucette R (eds): Biology and Pathology of Astrocyte-Neuron Interactions. New York, Plenum Publishing, 1993, pp 125-139.

$\checkmark 5$ Benarroch EE: Neurosteroids: endogenous modulators of neuronal excitability and plasticity. Neurology 2007;68:945-947.

$\checkmark 6$ Reddy DS: Neurosteroids: endogenous role in the human brain and therapeutic potentials. Prog Brain Res 2010;186:113-137.

$>7$ Zwain IH, Yen SS: Neurosteroidogenesis in astrocytes, oligodendrocytes, and neurons of cerebral cortex of rat brain. Endocrinology 1999; 140:3843-3852.
8 Irwin RW, Solinsky CM, Brinton RD: Frontiers in therapeutic development of allopregnanolone for Alzheimer's disease and other neurological disorders. Front Cell Neurosci 2014;8:203.

9 Jacobson M: Developmental Neurobiology, ed 3. New York, Plenum Press, 1991.

10 Sisk CL: Gonadal hormones organize the adolescent brain and behavior. Res Perspect Endocr Interact 2015;13:15-27.

$\checkmark 11$ Schipper H, Brawer JR, Nelson JF, Felicio LS, Finch CE: Role of the gonads in the histologic aging of the hypothalamic arcuate nucleus. Biol Reprod 1981;25:413-419.

12 Schipper HM, Lechan RM, Reichlin S: Glial peroxidase activity in the hypothalamic arcuate nucleus: effects of estradiol valerate-in duced persistent estrus. Brain Res 1990;507: 200-207.

$\checkmark 13$ Thornton J, Zehr JL, Loose MD: Effects of prenatal androgens on rhesus monkeys: a model system to explore the organizational hypothesis in primates. Horm Behav 2009;55: 633-645.

14 Wallen K: The organizational hypothesis: reflections on the 50th anniversary of the publication of Phoenix, Goy, Gerall, and Young (1959). Horm Behav 2009;55:561-565.
15 Plant TM: 60 years of neuroendocrinology: the hypothalamo-pituitary-gonadal axis. J Endocrinol 2015;226:T41-T54.

16 Bao AM, Swaab DF: Sexual differentiation of the human brain: relation to gender identity, sexual orientation and neuropsychiatric disorders. Front Neuroendocrinol 2011;32:214226.

17 Knickmeyer RC, Wang J, Zhu H, Geng X, Woolson S, Hamer RM, Konneker T, Styner $\mathrm{M}$, Gilmore JH: Impact of sex and gonadal steroids on neonatal brain structure. Cereb Cortex 2014;24:2721-2731.

18 Chancellor AM, Wroe SJ, Cull RE: Migraine occurring for the first time in pregnancy. Headache 1990;30:224-227.

19 Hauser L: Migraines and perimenopause: helping women in midlife manage and treat migraine. Nursing Womens Health 2012;16: 247-250.

20 Schipper HM, Jay CA, Abrams GM: Sex hormone, pituitary, parathyroid, and adrenal disorders and the nervous system; in Aminoff MJ, Josephson SA (ed): Neurology and General Medicine. San Diego, Academic Press, 2014, pp 369-397.

21 Loder E, Rizzoli P, Golub J: Hormonal management of migraine associated with menses and the menopause: a clinical review. Headache 2007;47:329-340. 
22 Herzog AG: Continuous bromocriptine therapy in menstrual migraine. Neurology 1997; 48:101-102.

23 Silberstein SD: Migraine and pregnancy. Neurol Clin 1997;15:209-231.

24 MacGregor EA: Perimenopausal migraine in women with vasomotor symptoms. Maturitas 2012;71:79-82.

25 Roy-O’Reilly M, McCullough LD: Sex differences in stroke: the contribution of coagulation. Exp Neurol 2014;259:16-27.

26 Schipper HM: Neurology of sex steroids and oral contraceptives. Neurol Clin 1986;4:721751.

27 Calhoun A: Combined hormonal contraceptives: is it time to reassess their role in $\mathrm{mi}-$ graine? Headache 2012;52:648-660.

-28 Simon JA, Hsia J, Cauley JA, Richards C, Harris F, Fong J, Barrett-Connor E, Hulley SB: Postmenopausal hormone therapy and risk of stroke: The Heart and Estrogen-progestin Replacement Study (HERS). Circulation 2001; 103:638-642.

-29 Viscoli CM, Brass LM, Kernan WN, Sarrel PM, Suissa S, Horwitz RI: A clinical trial of estrogen-replacement therapy after ischemic stroke. N Engl J Med 2001;345:1243-1249.

- 30 Shearman AM, Cooper JA, Kotwinski PJ, Humphries SE, Mendelsohn ME, Housman DE, Miller GJ: Estrogen receptor alpha gene variation and the risk of stroke. Stroke 2005; 36:2281-2282.

31 Fairweather D: Sex differences in inflammation during atherosclerosis. Clin Med Insights Cardiol 2014;8(suppl 3):49-59.

32 Mendelsohn ME, Karas RH: The protective effects of estrogen on the cardiovascular system. N Engl J Med 1999;340:1801-1811.

-33 Gonzales RJ: Androgens and the cerebrovasculature: modulation of vascular function during normal and pathophysiological conditions. Pflugers Arch 2013;465:627-642.

- 34 Meade TW, Berra A: Hormone replacement therapy and cardiovascular disease. Br Med Bull 1992;48:276-308.

- 35 Stubblefield PG: The effects on hemostasis of oral contraceptives containing desogestrel. Am J Obstet Gynecol 1993;168:1047-1052.

-36 Savitz SI, Schlaug G, Caplan L, Selim M: Arterial occlusive lesions recanalize more frequently in women than in men after intravenous tissue plasminogen activator administration for acute stroke. Stroke 2005;36: 1447-1451.

- 37 Maia DP, Fonseca PG, Camargos ST, Pfannes C, Cunningham MC, Cardoso F: Pregnancy in patients with Sydenham's Chorea. Parkinsonism Relat Disord 2012;18:458-461.

- 38 Munhoz RP, Kowacs PA, Soria MG, Ducci $\mathrm{RD}$, Raskin S, Teive HA: Catamenial and oral contraceptive-induced exacerbation of chorea in chorea-acanthocytosis: case report. Mov Disord 2009;24:2166-2167.

-39 Taylor KS, Cook JA, Counsell CE: Heterogeneity in male to female risk for Parkinson's disease. J Neurol Neurosurg Psychiatry 2007; 78:905-906.
40 Liu R, Umbach DM, Peddada SD, Xu Z, Troster AI, Huang X, Chen H: Potential sex differences in nonmotor symptoms in early drug-naive Parkinson disease. Neurology 2015;84:2107-2115.

-41 Martignoni E, Nappi RE, Citterio A, Calandrella D, Zangaglia R, Mancini F, Corengia E, Riboldazzi G, Polatti F, Nappi G: Reproductive life milestones in women with Parkinson's disease. Funct Neurol 2003;18:211-217.

42 Blanchet PJ, Fang J, Hyland K, Arnold LA, Mouradian MM, Chase TN: Short-term effects of high-dose 17beta-estradiol in postmenopausal PD patients: a crossover study. Neurology 1999;53:91-95.

43 Saunders-Pullman R, Gordon-Elliott J, Parides M, Fahn S, Saunders HR, Bressman S: The effect of estrogen replacement on early Parkinson's disease. Neurology 1999;52: 1417-1421.

44 Weiner WJ, Shulman LM, Singer C, Leifert R, Mash D: Menopause and estrogen replacement therapy in Parkinson's disease. Neurology 1996;46:A376.

45 Strijks E, Kremer JA, Horstink MW: Effects of female sex steroids on Parkinson's disease in postmenopausal women. Clin Neuropharmacol 1999;22:93-97.

46 Benedetti MD, Maraganore DM, Bower JH, McDonnell SK, Peterson BJ, Ahlskog JE, Schaid DJ, Rocca WA: Hysterectomy, menopause, and estrogen use preceding Parkinson's disease: an exploratory case-control study. Mov Disord 2001;16:830-837.

-47 Ragonese P, D’Amelio M, Salemi G, Aridon P, Gammino M, Epifanio A, Morgante L, Savettieri G: Risk of Parkinson disease in women: effect of reproductive characteristics. Neurology 2004;62:2010-2014.

48 Simon KC, Chen H, Gao X, Schwarzschild MA, Ascherio A: Reproductive factors, exog enous estrogen use, and risk of Parkinson's disease. Mov Disord 2009;24:1359-1365.

49 Nicoletti A, Nicoletti G, Arabia G, Annesi G, De Mari M, Lamberti P, Grasso L, Marconi R, Epifanio A, Morgante L, Cozzolino A, Barone P, Quattrone A, Zappia M: Reproductive factors and Parkinson's disease: a multicenter case-control study. Mov Disord 2011;26: 2563-2566.

50 di Michele F, Longone P, Romeo E, Lucchetti S, Brusa L, Pierantozzi M, Bassi A, Bernardi G, Stanzione P: Decreased plasma and cerebrospinal fluid content of neuroactive steroids in Parkinson's disease. Neurol Sci 2003; 24:172-173.

51 di Michele F, Luchetti S, Bernardi G, Romeo E, Longone P: Neurosteroid and neurotransmitter alterations in Parkinson's disease. Front Neuroendocrinol 2013;34:132-142.

52 Henri-Bhargava A, Melmed C, Glikstein R, Schipper HM: Neurologic impairment due to vitamin $\mathrm{E}$ and copper deficiencies in celiac disease. Neurology 2008;71:860-861.
53 Mizuta E, Yamasaki S, Nakatake M, Kuno S: Neuroleptic malignant syndrome in a parkinsonian woman during the premenstrual period. Neurology 1993;43:1048-1049.

-54 Schwabe MJ, Konkol RJ: Menstrual cycle-related fluctuations of tics in Tourette syndrome. Pediatr Neurol 1992;8:43-46.

55 Zupanc ML: Antiepileptic drugs and hormonal contraceptives in adolescent women with epilepsy. Neurology 2006;66(suppl 3):S37-45.

56 Saano V, Glue P, Banfield CR, Reidenberg P, Colucci RD, Meehan JW, Haring P, Radwanski E, Nomeir A, Lin CC, et al: Effects of felbamate on the pharmacokinetics of a low-dose combination oral contraceptive. Clin Pharmacol Ther 1995;58:523-531.

57 Herzog AG: Menstrual disorders in women with epilepsy. Neurology 2006;66(suppl 3): S23-S28

58 Crawford PM: Managing epilepsy in women of childbearing age. Drug Saf 2009;32:293307.

59 Guberman A: Hormonal contraception and epilepsy. Neurology 1999;53(suppl 1):S38S40.

60 Mengel HB, Houston A, Back DJ: An evaluation of the interaction between tiagabine and oral contraceptives in female volunteers. J Pharm Med 1994;4:141.

61 Dworetzky BA, Townsend MK, Pennell PB, Kang JH: Female reproductive factors and risk of seizure or epilepsy: data from the Nurses' Health Study II. Epilepsia 2012;53:e1-e4.

62 Finocchi C, Ferrari M: Female reproductive steroids and neuronal excitability. Neurol Sci 2011;32(suppl 1):S31-S35.

63 Herzog AG: Progesterone therapy in women with epilepsy: a 3-year follow-up. Neurology 1999;52:1917-1918.

64 Herzog AG, Fowler KM, Smithson SD, Kalayjian LA, Heck CN, Sperling MR, Liporace JD, Harden CL, Dworetzky BA, Pennell PB, Massaro JM, Progesterone Trial Study Group: Progesterone vs placebo therapy for women with epilepsy: a randomized clinical trial. Neurology 2012;78:1959-1966.

65 Zahn C: Catamenial epilepsy: clinical aspects. Neurology 1999;53(suppl 1):S34-S37.

- 66 Kerrigan JF, Shields WD, Nelson TY, Bluestone DL, Dodson WE, Bourgeois BF, Pellock JM, Morton LD, Monaghan EP: Ganaxolone for treating intractable infantile spasms: a multicenter, open-label, add-on trial. Epilepsy Res 2000;42:133-139.

-67 Laxer K, Blum D, Abou-Khalil BW, Morrell MJ, Lee DA, Data JL, Monaghan EP: Assessment of ganaxolone's anticonvulsant activity using a randomized, double-blind, presurgical trial design. Ganaxolone Presurgical Study Group. Epilepsia 2000;41:1187-1194.

68 Pieribone VA, Tsai J, Soufflet C, Rey E, Shaw K, Giller E, Dulac O: Clinical evaluation of ganaxolone in pediatric and adolescent patients with refractory epilepsy. Epilepsia 2007;48: 1870-1874.
Gonadal Hormones and Human

Neurological Disorders
Neuroendocrinology 2016;103:417-431 DOI: $10.1159 / 000440620$ 
69 Reddy DS, Woodward R: Ganaxolone, a prospective overview. Drugs Future 2004;29: 227-242.

-70 Mattila KM, Luomala M, Lehtimaki T, Laippala P, Koivula T, Elovaara I: Interaction between ESR1 and HLA-DR2 may contribute to the development of MS in women. Neurology 2001;56:1246-1247.

-71 Niino M, Kikuchi S, Fukazawa T, Yabe I, Tashiro K: Estrogen receptor gene polymorphism in Japanese patients with multiple sclerosis. J Neurol Sci 2000;179(suppl 1-2):7075.

-72 Savettieri G, Cittadella R, Valentino P, Manna I, Andreoli V, La Russa A, La Porta G, Ruscica F, Ragonese P, Pirritano D, Bonavita S, Tedeschi G, Quattrone A: Lack of association between estrogen receptor 1 gene polymorphisms and multiple sclerosis in southern Italy in humans. Neurosci Lett 2002;327: 115-118.

73 Dwosh E, Guimond C, Duquette P, Sadovnick $\mathrm{AD}$ : The interaction of MS and pregnancy: a critical review. Int MS J 2003;10:38-42.

74 Confavreux C, Hutchinson M, Hours MM, Cortinovis-Tourniaire P, Moreau T: Rate of pregnancy-related relapse in multiple sclerosis. Pregnancy in Multiple Sclerosis Group. N Engl J Med 1998;339:285-291.

-75 Alonso A, Clark CJ: Oral contraceptives and the risk of multiple sclerosis: a review of the epidemiologic evidence. J Neurol Sci 2009; 286:73-75.

76 Noorbakhsh F, Baker GB, Power C: Allopregnanolone and neuroinflammation: a focus on multiple sclerosis. Front Cell Neurosci 2014 8:134.

77 Orvieto R, Achiron R, Rotstein Z, Noy S, BarHava I, Achiron A: Pregnancy and multiple sclerosis: a 2-year experience. Eur J Obstet Gynecol Reprod Biol 1999;82:191-194.

78 Gold SM, Voskuhl RR: Estrogen and testosterone therapies in multiple sclerosis. Prog Brain Res 2009;175:239-251.

79 Selkoe DJ: The molecular pathology of Alzheimer's disease. Neuron 1991;6:487-498.

80 Henderson VW: Estrogen, cognition, and a woman's risk of Alzheimer's disease. Am J Med 1997;103:11S-18S.

-81 Honjo H, Tanaka K, Kashiwagi T, Urabe M, Okada H, Hayashi M, Hayashi K: Senile dementia-Alzheimer's type and estrogen. Horm Metab Res 1995;27:204-207.

82 Schneider LS, Farlow MR, Henderson VW, Pogoda JM: Effects of estrogen replacement therapy on response to tacrine in patients with Alzheimer's disease. Neurology 1996;46: 1580-1584

83 van Duijn CM: Hormone replacement therapy and Alzheimer's disease. Maturitas 1999; 31:201-205.

84 Wickelgren I: Estrogen stakes claim to cognition. Science 1997;276:675-678.
85 Henderson VW, Paganini-Hill A, Emanuel CK, Dunn ME, Buckwalter JG: Estrogen replacement therapy in older women. Comparisons between Alzheimer's disease cases and nondemented control subjects. Arch Neurol 1994;51:896-900.

86 Paganini-Hill A, Henderson VW: Estrogen deficiency and risk of Alzheimer's disease in women. Am J Epidemiol 1994;140:256-261.

87 Waring SC, Rocca WA, Petersen RC, O'Brien PC, Tangalos EG, Kokmen E: Postmenopausal estrogen replacement therapy and risk of AD: a population-based study. Neurology 1999;52:965-970

88 Massoud F, Yaffe K, Sano M: Estrogen; in Qizilbash N, Schneider LS, Chui H (ed): Evidence-Based Dementia Practice. Oxford, Blackwell, 2002, pp 523.

89 Kawas C, Resnick S, Morrison A, Brookmeyer $\mathrm{R}$, Corrada M, Zonderman A, Bacal C, Lingle DD, Metter E: A prospective study of estrogen replacement therapy and the risk of developing Alzheimer's disease: the Baltimore Longitudinal Study of Aging. Neurology 1997;48: 1517-1521.

90 Tang MX, Jacobs D, Stern Y, Marder K, Schofield P, Gurland B, Andrews H, Mayeux R: Effect of oestrogen during menopause on risk and age at onset of Alzheimer's disease. Lancet 1996;348:429-432.

91 Sherwin BB, Chertkow H, Schipper H, Nasreddine $\mathrm{Z}$ : A randomized controlled trial of estrogen treatment in men with mild cognitive impairment. Neurobiol Aging 2011;32: 1808-1817.

92 Cherrier MM, Matsumoto AM, Amory JK, Asthana S, Bremner W, Peskind ER, Raskind MA, Craft S: Testosterone improves spatial memory in men with Alzheimer disease and mild cognitive impairment. Neurology 2005; 64:2063-2068.

93 Tan RS, Pu SJ: A pilot study on the effects of testosterone in hypogonadal aging male patients with Alzheimer's disease. Aging Male 2003;6:13-17.

94 Cauley JA, Black DM, Barrett-Connor E, Harris F, Shields K, Applegate W, Cummings SR: Effects of hormone replacement therapy on clinical fractures and height loss: The Heart and Estrogen/Progestin Replacement Study (HERS). Am J Med 2001;110:442-450.

95 Shumaker SA, Legault C, Kuller L, Rapp SR, Thal L, Lane DS, Fillit H, Stefanick ML, Hendrix SL, Lewis CE, Masaki K, Coker LH; Women's Health Initiative Memory Study: Conjugated equine estrogens and incidence of probable dementia and mild cognitive impairment in postmenopausal women: Women's Health Initiative Memory Study. JAMA 2004;291:2947-2958.

96 Rosario ER, Pike CJ: Androgen regulation of beta-amyloid protein and the risk of Alzheimer's disease. Brain Res Rev 2008;57:444453.

97 Craig MC, Murphy DG: Estrogen therapy and Alzheimer's dementia. Ann NY Acad Sci 2010;1205:245-253.
98 Shao H, Breitner JC, Whitmer RA, Wang J, Hayden $\mathrm{K}$, Wengreen $\mathrm{H}$, Corcoran $\mathrm{C}$, Tschanz J, Norton M, Munger R, WelshBohmer K, Zandi PP, Cache County I: Hormone therapy and Alzheimer disease dementia: new findings from the Cache County Study. Neurology 2012;79:1846-1852.

-99 Marx CE, Keefe RS, Buchanan RW, Hamer RM, Kilts JD, Bradford DW, Strauss JL, Naylor JC, Payne VM, Lieberman JA, Savitz AJ, Leimone LA, Dunn L, Porcu P, Morrow AL, Shampine LJ: Proof-of-concept trial with the neurosteroid pregnenolone targeting cognitive and negative symptoms in schizophrenia. Neuropsychopharmacology 2009;34: 1885-1903.

100 Wolkowitz OM, Kramer JH, Reus VI, Costa MM, Yaffe K, Walton P, Raskind M, Peskind E, Newhouse P, Sack D, De Souza E, Sadowsky C, Roberts E, Research DH-AsDC: DHEA treatment of Alzheimer's disease: a randomized, double-blind, placebo-controlled study. Neurology 2003;60:1071-1076.

101 Krishnan V, Collop NA: Gender differences in sleep disorders. Curr Opin Pulm Med 2006;12:383-389.

102 Punjabi NM: The epidemiology of adult obstructive sleep apnea. Proc Am Thorac Soc 2008;5:136-143.

103 Polo-Kantola P, Erkkola R, Irjala K, Pullinen S, Virtanen I, Polo O: Effect of short-term transdermal estrogen replacement therapy on sleep: a randomized, double-blind crossover trial in postmenopausal women. Fertil Steril 1999;71:873-880.

104 Hachul H, Bittencourt LR, Andersen ML, Haidar MA, Baracat EC, Tufik S: Effects of hormone therapy with estrogen and/or progesterone on sleep pattern in postmenopausal women. Int J Gynaecol Obstet 2008; 103:207-212.

105 Friess E, Tagaya H, Trachsel L, Holsboer F, Rupprecht R: Progesterone-induced changes in sleep in male subjects. Am J Physiol 1997;272:E885-E891.

106 Dexter DD, Dovre EJ: Obstructive sleep apnea due to endogenous testosterone production in a woman. Mayo Clin Proc 1998;73: 246-248.

107 Korhonen K, Auvinen A, Lyytinen H, Ylikorkala O, Pukkala E: A nationwide cohort study on the incidence of meningioma in women using postmenopausal hormone therapy in Finland. Am J Epidemiol 2012 175:309-314.

108 Wahab M, Al-Azzawi F: Meningioma and hormonal influences. Climacteric 2003;6: 285-292.

109 Haddad G, Haddad F, Worseley K, Villemure JG: Brain tumours and pregnancy. Can J Neurol Sci 1991;18:231-236.

110 Hilbig A, Barbosa-Coutinho LM: Meningiomas and hormonal receptors: immunohistochemical study in typical and non-typical tumors. Arq Neuropsiquiatr 1998;56:193199. 
-111 Hsu DW, Efird JT, Hedley-Whyte ET: Progesterone and estrogen receptors in meningiomas: prognostic considerations. J Neurosurg 1997;86:113-120.

112 Lamberts SW, Koper JW, de Jong FH: The endocrine effects of long-term treatment with mifepristone (RU 486). J Clin Endocrinol Metab 1991;73:187-191.

113 Pines A: Hormone therapy and brain tumors. Climacteric 2011;14:215-216.

114 Batistatou A, Stefanou D, Goussia A, Arkoumani E, Papavassiliou AG, Agnantis NJ: Estrogen receptor beta (ERbeta) is expressed in brain astrocytic tumors and declines with dedifferentiation of the neoplasm. J Cancer Res Clin Oncol 2004;130:405-410.

115 Couldwell WT, Hinton DR, Surnock AA, DeGiorgio CM, Weiner LP, Apuzzo ML, Masri L, Law RE, Weiss MH: Treatment of recurrent malignant gliomas with chronic oral high-dose tamoxifen. Clin Cancer Res 1996;2:619-622.

116 Mastronardi L, Puzzilli F, Ruggeri A: Tamoxifen as a potential treatment of glioma. Anticancer Drugs 1998;9:581-586.
117 Pollack IF, DaRosso RC, Robertson PL, Jakacki RL, Mirro JR Jr, Blatt J, Nicholson S, Packer RJ, Allen JC, Cisneros A, Jordan VC: A phase I study of high-dose tamoxifen for the treatment of refractory malignant gliomas of childhood. Clin Cancer Res 1997;3: 1109-1115.

118 Frantzen C, Kruizinga RC, van Asselt SJ, Zonnenberg BA, Lenders JW, de Herder WW, Walenkamp AM, Giles RH, Hes FJ, Sluiter WJ, van Pampus MG, Links TP: Pregnancy-related hemangioblastoma progression and complications in von HippelLindau disease. Neurology 2012;79:793-796.

119 Kirby M, Zsarnovszky A, Belcher SM: Estrogen receptor expression in a human primitive neuroectodermal tumor cell line from the cerebral cortex: estrogen stimulates rapid ERK1/2 activation and receptor-dependent cell migration. Biochem Biophys Res Commun 2004;319:753-758.

120 Pors H, von Eyben FE, Sorensen OS, Larsen M: Longterm remission of multiple brain metastases with tamoxifen. J Neurooncology 1991;10:173-177.

121 Anderson KE, Spitz IM, Sassa S, Bardin CW, Kappas A: Prevention of cyclical attacks of acute intermittent porphyria with a long-acting agonist of luteinizing hormone-releasing hormone. N Engl J Med 1984;311:643-645.
22 Yamamori I, Asai M, Tanaka F, Muramoto A, Hasegawa H: Prevention of premenstrual exacerbation of hereditary coproporphyria by gonadotropin-releasing hormone analogue. Intern Med 1999;38:365-368.

123 Baker GS, Parsons WR, Welch JS: Endometriosis within the sheath of the sciatic nerve. Report of two patients with progressive paralysis. J Neurosurg 1966;25:652-655.

124 Floyd JR 2nd, Keeler ER, Euscher ED, McCutcheon IE: Cyclic sciatica from extrapelvic endometriosis affecting the sciatic nerve. J Neurosurg Spine 2011;14:281-289.

125 Mastrogiacomo I, Bonanni G, Menegazzo E, Santarossa C, Pagani E, Gennarelli M, Angelini C: Clinical and hormonal aspects of male hypogonadism in myotonic dystrophy. Ital J Neurol Sci 1996;17:59-65.

126 Goldenberg JN, Bradley WG: Testosterone therapy and the pathogenesis of Kennedy's disease (X-linked bulbospinal muscular atrophy). J Neurol Sci 1996;135:158-161. 